\section{The correlation between amplitude and speed measures in children's lever-pulling behavior}

GORDON N. CANTOR and SUNNAN K. KUBOSE, Institute of Child Behavior and Development, University of Iowa, lowa City, Iowa 52240

Forty first-grade children performed 25 lever-pulling responses, with measures being taken on each trial of starting time, movement time, and response amplitude (force exerted at the termination of the response chain). For each $S$, Pearson r values were computed relating starting speed and movement speed /reciprocals of the respective time values) to response amplitude across trials (excluding the first). The results provided virtually no evidence for a relationship between starting speed and amplitude $\sqrt{r}=+.058)$. In contrast, a rather substantial relationship between movement speed and amplitude was revealed $\sqrt{r}=+.511)$. Implications for lever studies employing children as Ss are discussed.

The stimulus-familiarization effect (SFE) in child behavior--i.e., the tendency for children to respond differentially on a motor task to a familiarized and to a nonfamiliarized stimulus-has to date been investigated using various speed measures as dependent variables. The typical finding (see Cantor, 1969) is that Ss respond faster to the nonfamiliarized than to the familiarized stimulus. The original aim of the present study was to incorporate a response-amplitude measure into the SFE paradigm in order to determine if differential responding to a familiarized and to a nonfamiliarized stimulus would be manifested in the latter type of measure as well. Evidence for the SFE in this experiment was obtained neither from an analysis performed on the amplitude data nor from analy ses run on two types of speed data. Various departures from procedures used in the earlier SFE studies may have been responsible for the failure to obtain any speed effects. Whether or not an amplitude SFE can be obtained remains an open question.

Inclusion of an amplitude measure together with two types of speed measures in this study provided an opportunity to examine the relationship of response amplitude to response speeds in children's lever-pulling behavior. Lever-pulling speed measures have been widely used in experimental child studies performed over the past several years, most notably in the area of frustration (see Ryan \& Watson, 1968). Since the theoretical formulations employed in such studies (e.g., Amsel, 1958, 1962) generate predictions of comparable effects when amplitude and at least certain types of speed indices are involved, it would appear to be worthwhile to ascertain the nature of the relationship, if any, existing between lever-pulling amplitude and speed scores. The present paper reports the results of such analyses performed on the data obtained in an experiment, the inception of which (as previously noted) was motivated by quite different interests.

\section{METHOD}

The Ss were 20 boys and 20 girls enrolled in first grade in an Iowa City public school.

The major pieces of apparatus consisted of a lever box, a stimulus-presentation device (together with necessary timing equipment), two electric clocks used to record response-time scores (to the nearest millisecond), and a target-transducerpolygraph system used to obtain amplitude data. The lever box was $10 \times 103 / 4 \times 19$ in. H. A vertical lever channel, $10 \mathrm{in}$. high, was located on the front face of the box. The lever, consisting of a ball (circumf. $=61 / 4$ in.) mounted on the end of a steel shaft, was spring-mounted so that in its resting position it protruded from the upper end of the channel. The target, an octagonal metal plate padded with foam rubber and covered by a rubber surface, measured approximately 5 in. across and rested on a $4 \times 5 \frac{3}{4} \times 4 \frac{1}{2}$ in. box located directly in front of and under the lever channel. The spatial relationships were such that depression of the lever brought its shaft into contact with the padded plate following an 8-in. excursion. In its terminal position, the lever shaft fell on a line parallel with the floor and in contact with approximately 4 in. of the target surface. The end of the shaft extended beyond the front edge of the target so that the ball did not contact the target. The target was mounted on a Statham Model UC3 transducer connected with a Model UL4-100 load cell accessory. Response amplitudes were recorded (in millimeters) on an Offner Dynograph a m plifier recorder. The stimulus-presentation device consisted of a $13 \frac{1}{2} \times 21 \frac{1}{2}$ in. vertical panel containing in its center a circular milk-glass aperture (diam $=31 / 2$ in.). On the back of the panel, behind the aperture, there was located a box containing two 6-W white bulbs. A green and a red light could be projected on the glass by use of Edmund Scientific $C_{0}$. filters (Nos. 874 and 821, respectively), each mounted between the aperture and one of the bulbs. The light panel was situated immediately to the left of the lever box, at an angle of approximately $130 \mathrm{deg}$ to the front surface of the latter.

Each $S$, run individually, first viewed 30 4-sec exposures of one of the two colored lights. Half of each sex group viewed green-light presentations, the remaining Ss viewing red-light exposures. During this phase, $S$ was seated, facing directly toward the stimulus panel.

Following the familiarization trials, $S$ was instructed to stand before the lever box with his right hand resting on the lever handle. $\mathrm{He}$ was told that E would say "Ready" and would then present a colored light-sometimes a green light and sometimes a red light. $S$ was told to watch the light carefully, and then to pull the lever down as quickly as he could upon offset of the light. $\mathrm{S}$ was given two lever-pulling practice trials, without stimulus presentations, and then was given 25 trials, each involving a 4-sec stimulus exposure. Half the Ss were given the familiarized stimulus on the first of these 25 trials, the remaining Ss being given the nonfamiliarized stimulus on that trial. For the remaining 24 trials, random orders of stimulus presentations were used, with the restriction that three familiarized and three nonfamiliarized stimulus presentations occur in each block of six trials. The intertrial interval in the motor task was approximately $10 \mathrm{sec}$. One clock was activated at the time of stimulus offset and terminated when $S$ moved the lever down a fraction of an inch, yielding a measure of starting time. A second clock, activated at the offset of the first clock, was terminated when the lever shaft contacted the target, yielding a mesasure of movement time.

\section{RESULTS AND DISCUSSION}

Each starting- and movement-time score for every $S$ was reciprocalized to produce speed scores. For the purpose of correlating speed and amplitude scores, only the data from the final 24 motor-task trials were used. For each of the $40 \mathrm{Ss}$, a Pearson product-moment correlation coefficient was computed for starting speed vs amplitude and for movement speed vs amplitude across the 24 trials in question.

Table 1 summarizes the results of the correlation calculations. With respect to the relationship between starting speed and amplitude, there were 25 positive correlations, only three of which were significant at the .05 level; there were 13 negative correlations, only two of these being significant. In contrast, with regard to the movement speed-amplitude correlations, 37 were positive in direction, 26 of these being significant; only three were negative, and none of the latter was significant. 
Table I

Summary of the Obtained Speed vs Amplitude Correlations

\begin{tabular}{|c|c|c|c|c|c|c|c|c|}
\hline & \multicolumn{8}{|c|}{ Comparison } \\
\hline & \multicolumn{4}{|c|}{ Start Speed vs Amplitude } & \multicolumn{4}{|c|}{ Movement Speed vs A mplitude } \\
\hline & \multicolumn{2}{|c|}{ Positive r's } & \multicolumn{2}{|c|}{ Negative r's } & \multicolumn{2}{|c|}{ Positive r's } & \multicolumn{2}{|c|}{ Negative r's } \\
\hline & Sig. & Not Sig. & Sig. & Not Sig. & Sig. & Not Sig. & Sig. & Not Sig. \\
\hline Frequency & 3 & 22 & 2 & 13 & 26 & 11 & 0 & 3 \\
\hline Range & $\begin{array}{r}+.426 \\
\text { to } \\
+.533 \\
\end{array}$ & $\begin{array}{c}+.010 \\
\text { to } \\
+.363 \\
\end{array}$ & $\begin{array}{c}-.405 \\
\text { to } \\
-.430 \\
\end{array}$ & $\begin{array}{c}-.002 \\
\text { to } \\
-.390 \\
\end{array}$ & $\begin{array}{l}+.404 \\
\text { to } \\
+.885 \\
\end{array}$ & $\begin{array}{c}+.062 \\
\text { to } \\
+.400 \\
\end{array}$ & -- & $\begin{array}{c}-.087 \\
\text { to } \\
-.148\end{array}$ \\
\hline
\end{tabular}

$r_{p .05}=.404(d f=22)$

Using a method suggested by Snedecor (1946), it was determined if computation of an average $\mathrm{r}$-value for each of the two sets of rs would be legitimate, this question being answered by testing the hypothesis that the several obtained rs could, in each case, be regarded as having been drawn from a common population. Since the null hypothesis could not be rejected in either case, average rs were computed. The corrected I-value (see Snedecor, 1946, p p. 151-155) for the starting speed-amplitude relationship was +.058 ; the corresponding value for the movement speed-amplitude relationship was +.511 .

It is apparent that the starting-speed and response-amplitude scores obtained in the present study were essentially unrelated, whereas a rather substantial positive relationship existed between the movement speed and amplitude scores. The use of speed measures, in a lever-pulling-task situation, to assess motivational effects (as in the child-frustration literature) would appear to receive some justification from this pattern of results. Under conditions in which no response tendencies of sufficient strength to compete successfully with the lever response are present, one would expect that a relatively high drive level should be reflected in relatively high speeds of responding (both starting and movement speeds) and relatively high response amplitudes. However, given a competitional situation, starting speeds in a high-drive group might well be depressed due to associative interference effects. With the response once having been initiated, though, the remainder of the response sequence in a high-drive group should be run off with vigor, as reflected in relatively fast movement-speed scores and relatively high amplitudes (see Rabinowitz, 1966, for a discussion of this issue as it bears on children's lever-response speeds).

Thus, the absence of a significant relationship between starting speeds and response amplitude (as measured) in the present study appears to be reconcilable with the the use of speed measures as indices of motivational effects. A comparable absence with regard to movement speed and amplitude would have been much more difficult to reconcile. The "driven" child, once having initiated his lever response, should move the lever quickly through its excursion and should "ram it home" with vigor. High movement speed coupled with low amplitude responding would suggest strongly the relevance of other (presumably nonmotivational) effects; so also would the reversed relationship, assuming it were physically possible to terminate the response with vigor after a relatively slow lever excursion-a seemingly unlikely possibility. (It is understood, of course, that sheer response vigor, perse, does not provide a sufficient basis for inferring motivational effects; the logic of the experimental situation must be taken into account-Brown, 1961; Cantor \& Whiteley, 1969.)

\section{REFERENCES}

AMSEL, A. The role of frustrative nonreward in noncontinuous reward situations. Psychological Bulletin, 1958, 55, 102-119.

AMSEL, A. Frustrative nonreward in partial reinforcement and discrimination learning: Some recent history and a theoretical extension. Psychological Review, 1962, 69, 306-328.

BROWN, J. S. The motivation of behavior. New York: McGraw-Hill, 1961.

CANTOR, G. N. Stimulus familiarization effect and the change effect in children's motor task behavior. Psychological Bulletin, 1969, 71, $144-160$.

CANTOR, G. N., \& WHITELEY, J.H. Effects of rewarding children's high- and low-amplitude motor responses. Psychonomic Science, 1969 , $16,211-212$.

RABINOWITZ, F. M. Conditioned stimulus duration and delay of reward as variables in a lever pulling situation. Journal of Experimental Child Psychology, 1966, 3, 225-234.

RYAN, T. J., \& WATSON, P. Frustrative nonreward theory applied to children's behavior. Psychological Bulfetin, 1968, 69, 111-125.

SNEDECOR, G. W. Statistical methods. (4th ed.) Ames, Iowa: The lowa State College Press, 1946.

\section{NOTE}

1. We are indebted to Mr. James D. Blank (Director of Elementary Education), Mr. Stanley Bishop (Principal, Coralville Central Elementary School), and the first-grade teachers of the Coralville School-all of the lowa City Community School District-for their fine cooperation. Kubose's present address: Department of Psychology, University of North Carolina at Greensboro. 